\title{
The clinical implication of cervical interspinous bursitis in the diagnosis of polymyalgia rheumatica
}

\section{Miguel A Gonzalez-Gay}

Polymyalgia rheumatica (PMR) is a relatively common inflammatory condition characterised by pain, aching and morning stiffness involving the shoulder and hip girdles and the neck. ${ }^{12}$ Patients are generally older than 50 years and the erythrocyte sedimentation rate (ESR) and C-reactive protein (CRP) are usually elevated. ${ }^{1}$ PMR may occur as an isolated disease or it may be observed in the setting of giant cell arteritis (GCA). ${ }^{3}$

Arthroscopic studies have confirmed the presence of synovitis in proximal joints of patients with PMR. ${ }^{4}$ However, the cause of musculoskeletal symptoms in these patients is not clearly defined because joint synovitis may only partially explain the diffuse discomfort along with involvement of periarticular structures. Interestingly, MRI and ultrasonography (US) studies disclosed bilateral inflammation of subacromial and subdeltoid bursae in association with synovitis of the glenohumeral joints and tenosynovitis of the biceps in patients with PMR. ${ }^{5}{ }^{6}$ More recently, using MRI and US, Cantini et al also confirmed the presence of trochanteric bursitis and, less commonly, iliopsoas and ischiogluteal bursitis in PMR patients. ${ }^{7}$ These studies support the pivotal role of the involvement of extraarticular synovial structures, in particular bursae, in PMR.

Shoulder pain is the most common and the presenting feature in patients with PMR. ${ }^{12}$ By contrast, pelvic and cervical involvement is less commonly observed. ${ }^{2}$ In this regard, in a population-based study from Northwest Spain, the frequency of shoulder girdle involvement was almost $100 \%$ in patients with isolated PMR and PMR associated with GCA. ${ }^{8}$ However, neck involvement was observed in $74 \%$ of individuals with isolated PMR and $67 \%$ of those with PMR associated with GCA. ${ }^{8}$

Correspondence to: Miguel A Gonzalez-Gay, Rheumatology Division, Hospital Xeral-Calde, c) Dr Ochoa s/n, 27004 Lugo, Spain; miguelaggay@hotmail.com
Population-based studies have confirmed that isolated PMR is generally a benign condition and most long-term survival studies have shown no increased mortality in patients with this condition. $^{9-11}$ Although the diagnosis of PMR is relatively straightforward when typical symptoms are present, ${ }^{12}$ none of the clinical and laboratory findings in PMR are specific. In this regard, polymyalgia manifestation may occur in patients with infections, neoplasms or other rheumatic diseases. ${ }^{13} 14$ Due to this, the search for findings that may support a diagnosis of PMR is of primary importance in some cases. It may be especially true when cervical pain is the predominant symptom. With respect to this, patients with crowned dens syndrome, condition related to microcrystalline deposition and radiological calcification of the cruciform ligament around the odontoid process, may present with acute cervical pain fever, neck stiffness and biological inflammatory syndrome. ${ }^{15}$ Additionally, we have recently reported seven patients with late onset undifferentiated spondyloarthritis presenting with PMR features. ${ }^{16}$

Taking these observations together, an important step forward in our understanding of the aetiology of cervical pain associated to PMR may be to establish the presence of objective data that may also support the presence of neck involvement in patients with PMR. Another important point may be to establish some specific features that may be useful in discriminating neck involvement in the setting of PMR from those observed in other conditions that may also yield cervical pain.

In the early and middle 1980s, Bywaters and colleagues reported three elegant studies addressing important information on spinal anatomy. ${ }^{17-19}$ In one of them, Bywaters described the presence of bursal spaces between the cervical interspinous processes at necropsy in 14 of 27 "normal" adult necks. ${ }^{17}$ The presence of bursae was most frequently located at the C6-C7 interspinous space. ${ }^{17}$ Interestingly, the cervical interspinous space was the seat of crystallopathic disease in 2 of these 14 individuals. Calcified deposits suggestive of calcium pyrophosphate dihydrate (CPPD) and hydroxyapatite crystal deposition in interspinous bursae were observed in one them, and areas occupied by CPPD crystals along with areas occupied by hydroxyapatite were found in the other. ${ }^{17}$ In the same necropsy study, Bywaters also aimed to determine whether cervical bursitis was present in five patients with juvenile chronic arthritis and in nine patients with adult-onset rheumatoid arthritis (RA). ${ }^{17}$ Interestingly, two of the nine patients with RA showed bursae between the interspinous processes but without any specific feature of RA involvement. ${ }^{17}$ However, cervical bursitis characterised by synovial lining hyperplasia and erosions of the spinous processes was demonstrated in two of the nine patients with the adult form of RA and also in two patients with juvenile chronic arthritis. ${ }^{17}$

The results reported by Bywaters raise a couple of questions that we should consider in the assessment of patients with rheumatic diseases with severe neck symptoms.

First, we wonder whether the clinical evidence of cervical interspinous bursitis may be of some help for establishing the diagnosis of inflammatory rheumatic diseases involving the lower cervical spine. Second, in a further step, it may be of interest to determine whether the presence of cervical bursitis at the lower cervical interspinous space may help discriminate specific inflammatory conditions with preferential involvement of the neck.

To address these issues, using MRI of the cervical spine, Salvarani et al ${ }^{20}$ (see page 758) studied 12 consecutive, untreated new patients with PMR along with a control group that included 13 patients with neck complaints (5 patients with fibromyalgia, 2 patients with cervical osteoarthritis and 6 patients with spondyloarthritis).

Interestingly, in all 12 patients with PMR, MRI disclosed the presence of fluid in the cervical interspinous bursae at the C5-C7 level, suggesting bursitis. ${ }^{20}$ Fluid accumulation in the cervical interspinous bursae at the same level was also found in 6 of the 13 control patients ( 3 patients with fibromyalgia, 2 with psoriatic spondylitis and 1 with cervical osteoarthritis). Of note, from four patients with primary ankylosing spondylitis, none showed cervical bursitis. ${ }^{20}$ More importantly, 
moderate accumulation of fluid (moderate bursitis) and/or sufficient quantity to stretch the walls of structures (marked bursitis) was more commonly observed in patients with PMR (10 of 12) than in the control group (4 of 13). ${ }^{20}$

Although these promising data need to be confirmed in a larger study, they provide evidence of the presence of lower interspinous cervical bursitis as the underlying cause of neck pain in patients with PMR.

A quick look at Salvarani et al's data raises additional considerations. Namely, the presence of bursitis by itself determined by cervical MRI may not be specific for PMR, as other conditions may also be associated with cervical bursitis. It may be the case that some patients have CPPD disease mimicking PMR. ${ }^{21}$ However, in the study by Salvarani et al, none of four patients with primary ankylosing spondylitis showed cervical bursitis. Taking into account this observation, evidence of bursitis in a cervical MRI might be useful in discriminating PMR from the subgroup of lateonset spondyloarthritis presenting with PMR manifestations. ${ }^{16}$ Another conclusion derived from Salvarani et al's study is that in the other conditions involving the neck different from PMR that have interspinous involvement, bursitis is generally mild. By contrast, moderate or severe interspinous bursitis was found in most patients with active PMR. Due to this, severe lower cervical interspinous bursitis might be of some help to support a diagnosis of PMR. ${ }^{21}$

Based on these promising results, clinicians may wonder when a cervical MRI should be performed in patients presenting with PMR features. From my point of view, since MRI is a fairly expensive procedure, typical cases of PMR should be treated without considering MRI studies. In general, an initial dosage of prednisone or its equivalent ranging between $10-20 \mathrm{mg} /$ day yields a dramatic and rapid improvement within the first
7 days (in most cases within the first 24 $72 \mathrm{~h}$ ) in the majority of patients with isolated PMR. ${ }^{19}{ }^{12}$ However, based on the results shown by Salvarani et al, clinicians might consider the possibility of performing a cervical MRI in patients with atypical PMR, in those with predominant cervical manifestations, or in individuals presenting with PMR and poor response to glucocorticoids.

A further step to be considered as a result of Salvarani et al's study may be to establish whether glucocorticoid therapy is able to decrease the severity of interspinous bursitis in PMR treated patients.

In conclusion, cervical MRI seems to be another additional tool to improve the diagnosis of PMR. However, further studies encompassing a larger number of patients are still needed.

Competing interests: None declared.

Accepted 25 February 2008

Ann Rheum Dis 2008;67:733-734

doi:10.1136/ard.2008.087999

\section{REFERENCES}

1. Chuang T-Y, Hunder GG, Ilstrup DM, Kurlan LT Polymyalgia rheumatica: a 10-year epidemiologic and clinical study. Ann Intern Med 1982;97:672-80.

2. Salvarani C, Cantini F, Boiardi L, Hunder GG. Polymyalgia rheumatica and giant-cell arteritis. N Engl J Med 2002:347:261-71.

3. Gonzalez-Gay MA. Giant cell arteritis and polymyalgia rheumatica: two different but often overlapping conditions. Semin Arthritis Rheum 2004; 33:289-93

4. Meliconi R, Pulsatelli L, Uguccioni M, Salvarani C, Macchioni P, Melchiorri C, et al. Leukocyte infiltration in synovial tissue from the shoulder of patients with polymyalgia rheumatica. Quantitative analysis and influence of corticosteroid treatment. Arthritis Rheum 1996:39:1199-207.

5. Salvarani C, Cantini F, Olivieri I, Barozzi L, Macchioni L, Niccoli L, et al. Proximal bursitis in active polymyalgia rheumatica. Ann Intern Med 1997;127:27-31.

6. Cantini F, Salvarani C, Olivieri I, Niccoli L, Padula A Macchioni L, et al. Shoulder ultrasonography in the diagnosis of polymyalgia rheumatica: a case-control study. J Rheumatol 2001;28:1049-55.

7. Cantini F, Niccoli L, Nannini C, Padula A, Olivieri I, Boiardi L, et al. Inflammatory changes of hip synovial structures in polymyalgia rheumatica. Clin Exp Rheumatol 2005;23:462-8.
8. González-Gay MA, García-Porrúa C, VázquezCaruncho M. Polymyalgia rheumatica in biopsy proven giant cell arteritis does not constitute a different subset but differs from isolated polymyalgia rheumatica. J Rheumatol 1998;25:1750-5.

9. González-Gay MA, García-Porrúa C, VázquezCaruncho M, Dababneh A, Hajeer A, Ollier WE. The spectrum of polymyalgia rheumatica in northwestern Spain: incidence and analysis of variables associated with relapse in a 10 year study. $J$ Rheumatol 1999;26:1326-32.

10. Gran JT, Myklebust G, Wilsgaard T, Jacobsen BK. Survival in polymyalgia rheumatica and temporal arteritis: a study of 398 cases and matched population controls. Rheumatology (Oxford) 2001:40:1238-42.

11. Doran MF, Crowson CS, O'Fallon WM, Hunder GG, Gabriel SE. Trends in the incidence of polymyalgia rheumatica over a 30 year period in Olmsted County. Minnesota, USA. J Rheumatol 2002;29:1694-7.

12. Gonzalez-Gay MA, Garcia-Porrua C, Salvarani C, Hunder GG. Diagnostic approach in a patient presenting with polymyalgia. Clin Exp Rheumatol 1999;17:276-8

13. Gonzalez-Gay MA, Garcia-Porrua C, Salvarani C, Olivieri I, Hunder GG. The spectrum of conditions mimicking polymyalgia rheumatica in Northwestern Spain. J Rheumatol 2000;27:2179-84.

14. González-Gay MA, García-Porrúa C, Salvarani C, Olivieri I, Hunder GG. Polymyalgia manifestations in different conditions mimicking polymyalgia rheumatica. Clin Exp Rheumatol 2000;18:755-9.

15. Aouba A, Vuillemin-Bodaghi V, Mutschler C, De Bandt M. Crowned dens syndrome misdiagnosed as polymyalgia rheumatica, giant cell arteritis, meningitis or spondylitis: an analysis of eight cases. Rheumatology (Oxford) 2004;43:1508-12.

16. Olivieri I, Garcia-Porrua C, Padula A, Cantini F, Salvarani C, Gonzalez-Gay MA. Late onset undifferentiated spondyloarthritis presenting with polymyalgia rheumatica features: description of seven cases. Rheumatol Int 2007;27:927-33.

17. Bywaters EGL. Rheumatoid and other diseases of the cervical interspinous bursae, and changes in the spinous processes. Ann Rheum Dis 1982;41:360-70.

18. Bywaters EGL and Evans S. The lumbar interspinous bursae and Baastrup's syndrome. An autopsy study. Rheumatol Int 1982;2:87-96.

19. François RJ, Bywaters EGL, Aufdermaur M Illustrated glossary for spinal anatomy. With explanations and a French and German translation. Rheumatol Int 1985;5:241-5.

20. Salvarani C, Barozzi L, Cantini F, Niccoli L, Boiardi L, Valentini $\mathrm{M}$, et al. Cervical interspinous bursitis in active polymyalgia rheumatica. Ann Rheum Dis 2008;67:758-61

21. Pego-Reigosa JM, Rodriguez-Rodriguez M, HurtadoHernandez Z, Gromaz-Martin J, Taboas-Rodriguez D, Millan-Cachinero C, et al. Calcium pyrophosphate deposition disease mimicking polymyalgia rheumatica: a prospective followup study of predictive factors for this condition in patients presenting with polymyalgia symptoms. Arthritis Rheum 2005;53:931-8. 